\title{
Alterações no Código Florestal Brasileiro Favorecerão Espécies Não-nativas de Peixes de Água Doce
}

\author{
Changes in the Brazilian Forest Law will Promote \\ Non-native Species of Freshwater Fish
}

\section{André Lincoln Barroso de Magalhães ${ }^{1, *}$, Lilian Casatti \& Jean Ricardo Simões Vitule ${ }^{3}$}

\author{
${ }^{1}$ Centro de Ciências Biológicas e da Saúde, Centro Universitário UNA, Belo Horizonte, MG, Brasil \\ ${ }^{2}$ Departamento de Zoologia e Botânica, Universidade Estadual Paulista - UNESP, São José do Rio Preto, SP, Brasil \\ ${ }^{3}$ Laboratório de Ecologia e Conservação - LEC, Departamento de Engenharia Ambiental, \\ Universidade Federal do Paraná - UFPR, Curitiba, PR, Brasil
}

Recentemente tem-se discutido no Brasil as alterações potenciais que a nova proposta para o Código Florestal Brasileiro (Projeto de Lei no 1876/99) trará para recursos hídricos, campos rupestres e de altitude e para diversos grupos de organismos com importância econômica e ecossistêmica (Silva et al. 2011). Permeando essas discussões, faz-se necessário debater de forma mais direta as alterações previstas nesta nova proposta no contexto específico das invasões biológicas. Procuramos demonstrar, com exemplos embasados na literatura científica (teorias e dados empíricos), como as alterações propostas pelo novo substitutivo do relator da Comissão Especial da Câmara dos Deputados de maio de 2011 no atual Código Florestal Brasileiro, favorecerão espécies não-nativas de peixes, amplificando seus impactos nas diferentes escalas espaciais, temporais e biológicas (de genoma à ecossistema).

Quatro pontos das alterações vigentes serão discutidos com maior detalhe por estarem diretamente relacionados ao favorecimento das espécies não-nativas de peixes.

\section{Define de Interesse Social Qualquer Produção de Alimentos ou Pecuária Extensiva para Desmatamento em APPs (Artigo $3^{\circ}$, Número IV, g)}

Em decorrência desse artigo, o déficit de cobertura florestal nas Áreas de Proteção Permanentes (APPs) será significativamente ampliado. Nos corpos d'água, isso acarretaria assoreamento do canal, redução do volume e fluxo de água. Essas condições favorecerão as espécies

\footnotetext{
*Send correspondence to: André Lincoln Barroso de Magalhães Centro de Ciências Biológicas e da Saúde,

Centro Universitário UNA, Rua Guajajaras, 175, Centro,

CEP 30180-100, Belo Horizonte, MG, Brasil

E-mail: andrebio@terra.com.br
}

não-nativas generalistas e oportunistas, especialmente peixes com habilidades para consumir detritos orgânicos, o item alimentar dominante em tais condições (Rocha et al. 2009). Exemplos desses fenômenos são a dominância de Poecilia reticulata em 47 riachos no estado de São Paulo, em função de modificações antrópicas que geraram algumas das condições acima listadas (Casatti et al. 2009).

\section{Autoriza a Ocupação de Pessoas nas APPs Urbanas (Artigo $3^{\circ}$, Número XVII, h)}

Autorizações de ocupação humana nas APPs, especialmente as urbanas, certamente resultarão em proporcional tendência de aumento de introduções deliberadas de peixes não-nativos. Nossa previsão se baseia no fato de que a presença de peixes não-nativos em corpos d'água está diretamente relacionada à ocupação humana (Leprieur et al. 2008). Exemplos disso são as introduções de Xiphophorus variatus, P. sphenops e Trichogaster trichopterus no córrego da Serra, Belo Horizonte, Minas Gerais (Chaves \& Magalhães 2010).

\section{Possibilidade de Intervenção ou} Supressão de Vegetação em APPs em Situações de Utilidade Pública, de Interesse Social ou de Baixo Impacto Ambiental (Artigo $8^{\circ}$ ) e de Possibilidade de Manutenção de Atividades Florestais, Culturas de Espécies Lenhosas e Pastoreio Extensivo em Topos de Morros, Montes, Montanhas, Serras e Regiões com Altitudes Superiores a $1.800 \mathrm{~m}$ (Artigo 10)

Essas possibilidades incentivarão a implementação de empreendimentos como hotéis-fazenda e/ou turismo 
"ecológico" que, via de regra, incorporam o cultivo de peixes em tanques rústicos e familiares, próximos aos corpos d'água. Nessas áreas de maior altitude, é comum a truticultura ou mesmo a soltura direta em ambiente natural de trutas e outras espécies de hábitos similares com alto potencial invasor para práticas de pesca esportiva ou "pesca-e-solte" (Vitule 2009).

A presença de peixes não-nativos em regiões de elevadas altitudes é preocupante, pois os córregos e cabeceiras que predominam nesses locais têm poucas espécies nativas e em decorrência apresentam baixa resistência ambiental à invasão biológica. Além disso, a presença de peixes não-nativos predadores pode provocar o fenômeno de "Armadilha Evolutiva", ou seja, pela ausência histórica do novo predador no ambiente, espécies nativas são evolutivamente vulneráveis às espécies não-nativas predadoras (Schlaepfer et al. 2002). Por exemplo, Oncorhynchus mykiss representa ameaça ao cascudo endêmico Pareiorhaphis garbei nas cabeceiras do rio Macaé, Rio de Janeiro (Lazzarotto \& Caramaschi 2009).

\section{Anistia Geral aos Proprietários que Desrespeitaram os Limites Legais em Termos de Reservas Legais e/ou das APPs (Artigo $30^{\circ}$ )}

Medidas como essa incentivarão o desmatamento, fato que certamente facilitará ainda mais a construção de pisciculturas familiares ou de pequeno porte nas proximidades dos corpos d'água, empreendimento profundamente incentivado pelos últimos e atual Governo Federal através do Ministério da Pesca e Aquicultura, além da piscicultura ornamental, que vem apresentando-se muito atrativa como atividade de aquicultura no Brasil, com crescimento anual de $20 \%$ (Camargo \& Pouey 2005).

É fato que a maioria dos piscicultores brasileiros já mantém, há muito tempo, a prática de estabelecer seus tanques nas proximidades de corpos d'água e dentro das APPs. Este fato, via de regra, favorece o rompimento ou transbordamento destes em razão de picos de cheias não previstos durante a construção. Nestas áreas, a falta de cuidado durante o manejo dos tanques também tem sido motivo para o escape de indivíduos para os ambientes naturais. Essas fugas provocaram mudanças na estrutura da comunidade natural residente do riacho Santo Antônio, Minas Gerais, onde $P$. reticulata e $X$. hellerii foram as espécies mais abundantes em 2005, com 5.282 e 1.178 exemplares, respectivamente (Magalhães 2010).

Os quatro exemplos acima mencionados certamente podem acarretar nos fenômenos de homogeneização/ diferenciação biótica, assuntos ainda pouco estudados no Brasil. Homogeneização biótica pode ocorrer por meio da introdução das mesmas espécies não-nativas em locais diferentes, gerando aumento da similaridade entre comunidades invadidas e assim provocando a diminuição de diversidade beta (i.e. a variabilidade entre habitats). Isto seria esperado, por exemplo, no caso da introdução de espécies de peixes largamente utilizadas na piscicultura do país como Oreochromis niloticus e Cyprinus carpio. Em contrapartida, o crescimento da piscicultura ornamental em vários estados, tenderá a confirmar a diferenciação biótica. Diferenciação biótica é o fenômeno inverso da homogeneização, sendo provocada pela introdução de diferentes espécies não-nativas em locais díspares, levando a um decréscimo da similaridade nas comunidades invadidas e incrementando a diversidade beta (Vitule 2009). Alguns exemplos interessantes e pouco divulgados são o polo de piscicultura ornamental de Muriaé, Minas Gerais, onde a fuga massiva de mesmas espécies não-nativas como $P$. reticulata, $P$. sphenops, $X$. maculatus, $X$. variatus, $X$. hellerii, Misgurnus anguillicaudatus, Gymnocorymbus ternetzi, Danio rerio, Danio sp., Carassius auratus, C. carpio, Puntius conchonius, P. tetrazona, Tanichthys albonubes e Trichogaster lalia em quatro riachos distintos, provocou homogeneização biótica. Por outro lado, em três riachos na mesma região foi verificada diferenciação biótica devido ao grande número de solturas indiscriminadas de diferentes espécies ornamentais não-nativas (Magalhães 2010). Isso pode favorecer a propagação secundária de espécies invasoras (e.g. patógenos e parasitos) e intensificar a competição interespecífica ameaçando assim, a existência de espécies nativas raras e endêmicas. Ambos os processos podem influenciar as mudanças na atual composição de espécies e acelerar a taxa de homogeneização biótica regional e global. A homogeneização biótica é uma faceta distinta e obscura da atual crise da biodiversidade, mas que certamente apresenta significativos efeitos ecológicos, evolutivos e conseqüências sociais. Assim, com a homogeneização biótica esperamos um colapso na biodiversidade nacional, devido a um esperado aumento da similaridade genética, taxonômica ou funcional entre regiões e biomas distintos ao longo do tempo.

\section{Conclusões}

Concluímos que as novas mudanças propostas para o Código Florestal Brasileiro apresentam-se potencialmente favoráveis a: i) promover a degradação de ambientes aquáticos, favorecendo espécies não-nativas de peixes, notadamente poecilídeos, popularmente conhecidos como barrigudinhos; ii) aumentar a tendência de introduções de peixes devido à ocupação humana nas APPs; iii) provocar a extinção da escassa ictiofauna de regiões de elevada altitude proporcionada pela presença de espécies não-nativas predadoras como as trutas O. mykiss; e iv) aumentar o número de empreendimentos de aquicultura perigosamente próximos ao corpos d'água, com isso, ampliando as taxas de introduções de peixes não-nativos, acarretando em mudanças na estrutura das comunidades residentes, homogeneização/diferenciação bióticas, representando um enorme prejuízo ambiental para o Brasil e notoriamente para as futuras gerações. Há também uma série de efeitos sutis e/ou imprevisíveis em relação a peixes não-nativos de água doce, notoriamente em termos de longa escala 
temporal. Assim, espécies de peixes não-nativos são mundialmente reconhecidas como um agente real de ameaça de extinção; sinergicamente com a perda e fragmentação de habitat, alterações hidrológicas, mudanças climáticas, a sobrexploração e poluição.

Mediante a todo o exposto, cabe ressaltar alguns fatos que tornam as ameaças relacionadas de suma importância para a sociedade brasileira e para as futuras gerações: i) a água doce representa menos de $0,8 \%$ da superfície da Terra e suporta mais de $6 \%$ de todas as espécies descritas no planeta; ii) 40\% das espécies de peixes conhecidos vive em ambientes de água doce, e o Brasil é o país mais rico em termos de espécies de peixes e de biodiversidade geral de água doce do mundo; e iii) a biodiversidade em água doce constitui um precioso recurso natural em termos de valor econômico, cultural, estético, científico e educativo; em escalas regional, nacional e global. Infelizmente, os ecossistemas de água doce são os mais ameaçados em função das demandas de água, e impactos humanos negativos sobre a integridade ecológica associados às introduções de espécies não-nativas.

Alertamos que os prejuízos ambientais proporcionados pelas introduções de peixes através do vetor humano poderão não ter fim, pois uma vez ocorridas, invasões biológicas em ambientes aquáticos são praticamente impossíveis de serem revertidas.

\section{Agradecimentos}

Agradecemos e estamos em débito com o Dr. Sidinei M. Thomaz, pela leitura crítica e sugestões de melhoria no texto. Agradecemos também ao Dr. José Alexandre F. Diniz-Filho, por ter considerado nossa proposta de forum.

\section{Referências}

Camargo SGO \& Pouey JLOF, 2005. Aquicultura - um mercado em expansão. Revista Brasileira de Agrociência, 11:393-396.
Casatti L, Ferreira CP \& Carvalho FR, 2009. Grass-dominated stream sites exhibit low fish species diversity and dominance by guppies: an assessment of two tropical pasture river basins. Hydrobiologia, 632:273-283. http://dx.doi.org/10.1007/ s10750-009-9849-y

Chaves MR \& Magalhães ALB, 2010. Peixes ornamentais não-nativos introduzidos por aquaristas em um parque urbano de Belo Horizonte, MG. Boletim da Sociedade Brasileira de Ictiologia, 101:6-7.

Lazzarotto H \& Caramaschi EP, 2009. Introdução da truta no Brasil e na bacia do rio Macaé, Estado do Rio de Janeiro: histórico, legislação e perspectivas. Oecologia Brasiliensis, 13:649-659. http://dx.doi.org/10.4257/oeco.2009.1304.08

Leprieur F et al., 2008. Fish invasions in the world's river systems: when natural processes are blurred by human activities. PLoS Biology, 6:e28. PMid:18254661. PMCid:2225436. http:// dx.doi.org/10.1371/journal.pbio.0060028

Magalhães ALB, 2010. Efeitos da introdução de peixes ornamentais não-nativos em bacias higrográficas de Minas Gerais. [Tese de Doutorado]. Programa de Pós-Graduação em Ecologia, Conservação e Manejo de Vida Silvestre, Universidade Federal de Minas Gerais.

Rocha FC et al., 2009. Fish assemblages in stream stretches occupied by cattail (Typhaceae, Angiospermae) stands in Southeast Brazil. Neotropical Ichthyology, 7:241-250. http:// dx.doi.org/10.1590/S1679-62252009000200016

Schlaepfer MA, Runge MC \& Sherman PW, 2002. Ecological and evolutionary traps. Trends in Ecology and Evolution, 17:474480. http://dx.doi.org/10.1016/S0169-5347(02)02580-6

Silva JAA et al. 2011. O Código florestal e a ciência: contribuições para o diálogo. São Paulo: Sociedade Brasileira para o Progresso da Ciência, Academia Brasileira de Ciências.

Vitule JRS, 2009. Introduction of fishes in Brazilian continental ecosystems: Review, comments and suggestions for actions against the almost invisible enemy. Neotropical Biology and Conservation, 4:111-122. http://dx.doi.org/10.4013/ nbc.2009.42.07

Recebido: Junho 2010

Primeira Decisão: Junho 2010

Aceito: Junho 2010 
